\title{
Developmental changes in IGF-I and MyoG gene expression and their association with meat traits in sheep
}

\author{
W. Sun ${ }^{1,2}$, R. Su${ }^{1}$, D. Li ${ }^{1}$, H.H. Musa ${ }^{3}$, Y. Kong ${ }^{1}$, J.T. Ding ${ }^{1}$, Y.H. Ma ${ }^{2}$, \\ L. Chen ${ }^{4}$, Y.F. Zhang ${ }^{4}$ and W.Z. Wu ${ }^{4}$ \\ ${ }^{1}$ Animal Science and Technology College, Yangzhou University, Yangzhou, China \\ ${ }^{2}$ Institute of Animal Science, Chinese Academy of Agricultural Sciences, \\ Beijing, China \\ ${ }^{3}$ Faculty of Medical Laboratory Sciences, University of Khartoum, \\ Khartoum, Sudan \\ ${ }^{4}$ Animal Science \& Veterinary Medicine Bureau of Suzhou City, Suzhou, China \\ Corresponding author: W. Sun \\ E-mail: dkxmsunwei@163.com
}

Genet. Mol. Res. 13 (2): 2772-2783 (2014)

Received February 6, 2013

Accepted June 20, 2013

Published April 14, 2014

DOI http://dx.doi.org/10.4238/2014.April.14.6

\begin{abstract}
In the present study, real time-polymerase chain reaction was applied to analyze the expression of IGF-I and MyoG genes in $\mathrm{Hu}$ sheep longissimus dorsi at different growth stages and their association with meat traits. Expression of the IGF-I gene in $\mathrm{Hu}$ sheep differed significantly between males and females at the two day-old $(0.01<\mathrm{P}<0.05)$, one-month old $(0.01<\mathrm{P}<0.05)$, and three month-old $(\mathrm{P}<0.01)$ stages. IGF-I gene expression in male longissimus muscles was higher than that of females at all growth stages, except for the three month-old stage. There was no significant difference $(\mathrm{P}>0.05)$ between males and females at any growth stage in expression of the MyoG gene. MyoG gene expression in male longissimus muscles tended to be higher than that of females at all growth stages, except for the six month-
\end{abstract}


old stage. IGF-I gene expression was significantly and positively correlated with live weight $(\mathrm{P}<0.01)$ and carcass weight $(0.01<$ $\mathrm{P}<0.05)$, and was non-significantly positively correlated with net meat weight $(\mathrm{P}>0.05)$. In contrast, MyoG gene expression was nonsignificantly and positively correlated with live weight, carcass, and net meat weight $(\mathrm{P}>0.05)$. Carcass traits showed highly significant positive correlations $(\mathrm{P}<0.01)$. Furthermore, expressions of IGF-I and $\mathrm{MyoG}$ genes showed highly significant positive correlations ( $\mathrm{P}$ $<0.01$ ). We conclude that the expressions of IGF-I and MyoG genes are significantly and positively correlated with early muscle traits of $\mathrm{Hu}$ sheep.

Key words: Hu sheep; IGF-I; MyoG; Gene expression; Carcass trait

\section{INTRODUCTION}

Because the profitability of sheep production for meat depends largely on lamb weight, selection objectives should concentrate on these traits (Tosh and Kemp, 1994). Quantitative traits are often controlled by multiple genes. Localization of quantitative trait loci can be accomplished by linkage disequilibrium analysis or by adopting a candidate gene approach. Candidate genes are those with known biological functions related to the development or physiology of an important trait (Rothschild et al., 1997). The gene encoding insulin-like growth factor 1 (IGF-1) is seen as a promising candidate gene for marker-assisted selection of growth traits (Zhang et al., 2008). IGF-1 is a mediator of many biological effects; for example, it increases the absorption of glucose, stimulates myogenesis, inhibits apoptosis, participates in the activation of cell cycle genes, increases the synthesis of lipids, stimulates the production of progesterone in granular cells, and intervenes in the synthesis of DNA, protein, RNA, and in cell proliferation (Reyna et al., 2010). In humans, pigs, goats, rats, and chickens, the IGF1 nucleotide sequence is approximately 70-90 kb in length (Shimatsu and Rotwein, 1987; Kajimoto and Rotwein, 1991; Rose, 2002). The exon number of this gene differs among species; goats, pigs, and sheep have 1-6 exons (Mikawa et al., 1995), and humans and rats have 1-55 exons (Rotwein et al., 1986)

The skeletal muscle-specific gene, myogenin (Myog), is a key developmental regulator of skeletal muscle formation, and is one of the best-studied tissue-specific genes. Myog encodes a transcription factor of the basic-helix loop-helix (bHLH) protein family (Meadows et al., 2011). Expression of the Myog gene is restricted to skeletal muscle cells, where the transcriptional activator turns on a gene expression program that permits the transition from proliferating myoblasts to differentiating myotubes (Cao et al., 2010). The strict temporal and spatial regulation on Myog expression in the embryo makes it an ideal gene with which to study the developmental regulation of tissue-specific expression (Faralli and Dilworth, 2012).

$\mathrm{Hu}$ sheep from China is one of the few high-fecundity sheep breeds in the world. It is characterized by early sexual maturity, high fecundity, low lean meat percentage, and low growth rate. Therefore, it is considered as one of the protected sheep breeds in China (Zhang, 2003). Several studies related to tissue expression profiles in domestic sheep 
have been conducted recently, with most focusing on the expression of intramuscular fat content. In the present study, we investigated the effect of sex and different growth stages (two day-old, one month-old, two month-old, three month-old, four month-old, and six month-old) on the expression of IGF-I and MyoG genes in longissimus dorsi tissues of Hu sheep.

\section{MATERIAL AND METHODS}

\section{Experimental animals}

The $36 \mathrm{Hu}$ sheep used in this study were reared under the same conditions, and their diets contained adequate minerals and vitamins. Animals were slaughtered at six different growth stages ( 2 days, 1, 2, 3, 4, and 6 months), including six animals per stage with equal numbers of males and females. Samples were collected from longissimus dorsi muscle tissues, and all tissue samples were immediately frozen in liquid nitrogen after collection and stored at $-80^{\circ} \mathrm{C}$ until RNA isolation. Live weight, carcass weight, and net meat weight were measured from all animals.

\section{Real-time polymerase chain reaction (RT-PCR)}

Total RNA was extracted from longissimus dorsi muscle tissues according to Trizol Regent Kit instructions (Takara Biotechnology Dalian, Co. Ltd., China). The concentration of RNA was measured using a Nano Drop ND-1000 Spectrophotometer (Nano Drop Technologies, Wilmington, DE, USA) with a purity $\left(\mathrm{A}_{260} / \mathrm{A}_{280}\right)$ of $>1.8$, and total RNA was detected by $1.2 \%$ agarose gel electrophoresis (Figure 1). Two hundred fifty nanograms total RNA from each sample were transcribed into cDNA using the reverse transcription kit according to manufacturer instructions. Real-time PCR was performed on the FQ-PCR ABI 7900 system for IGF-I, MyoG, and 18S genes, according to standard protocols with the primers indicated in Table 1. The 18S ribosomal RNA gene (eukaryon) was used as a reference gene to analyze the expression of IGF-I and MyoG genes. Annealing temperatures ranged from $53^{\circ}-63^{\circ} \mathrm{C}$, and primer concentrations were optimized according to the SYBR Green I kit. The optimal reaction used was $10 \mu \mathrm{L}$, containing 0.2

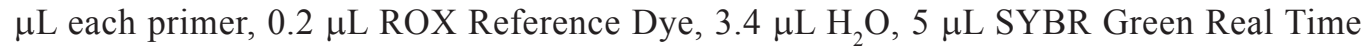
PCR Master Mix, and $1 \mu \mathrm{L}$ cDNA template. The PCR conditions were 40 cycles of $15 \mathrm{~s}$ at $95^{\circ} \mathrm{C}, 5 \mathrm{~s}$ at $95^{\circ} \mathrm{C}$, and $30 \mathrm{~s}$ at $60^{\circ} \mathrm{C}$. For the negative control, $1 \mu \mathrm{L}$ sterile water (instead of template) was used, and three parallel experiments were run for every sample. The fluorescent signal was analyzed with computer software, and signals were transformed into cycle threshold $(\mathrm{Ct})$ values for IGF-I and MyoG genes.

\section{Statistical analysis}

SPSS 16.0 was used to calculate $\mathrm{Ct}$ values and standard errors among replicated samples. Difference in relative gene expression levels were analyzed using the $2^{-\Delta \Delta \mathrm{Ct}}$ method (Liu, 2007): $\mathrm{Ct}_{\text {target gene }}-\mathrm{Ct}_{\text {reference gene. }}$. For comparisons of Hu sheep of the same age but different gender, the $\Delta \Delta \mathrm{Ct}$ was calculated as: $\Delta \mathrm{Ct}_{\text {male }}-\Delta \mathrm{Ct}_{\text {female }}$. For comparisons of Hu sheep of the same 
sex but different ages, the $\Delta \Delta \mathrm{Ct}$ was calculated as: $\Delta \mathrm{Ct}_{\text {all other stages }}-\Delta \mathrm{Ct}_{2 \text { day-old stage }}$ The $2^{-\Delta \Delta \mathrm{Ct}}$ value represented differential expression of the target gene between the experimental group and control group. Two-factor analysis of variance (ANOVA) was used to measure the interaction between gender and various developmental stages after birth, and no significant interactions were observed either in MyoG $(\mathrm{F}=1.58, \mathrm{P}=0.102)$ or IGF-I $(\mathrm{F}=1.22, \mathrm{P}=0.306)$. We next focused on the comparison between genders at the same growth stage and different growth stages within the same gender, respectively. The goal of these analyses was to explore the effect of gender and growth stage on expressions of the MyoG and IGF-I genes. Data of sheep of the same age but different genders were compared with the Student's $t$-test, whereas data of individuals within the same sex but of different ages were compared by one-way ANOVA. The mRNA transcriptional quantity is represented as means \pm standard error. Furthermore, the $\Delta \mathrm{Ct}$ histogram was used to verify whether $\Delta \mathrm{Ct}$ was negatively related with transcriptional quantity.

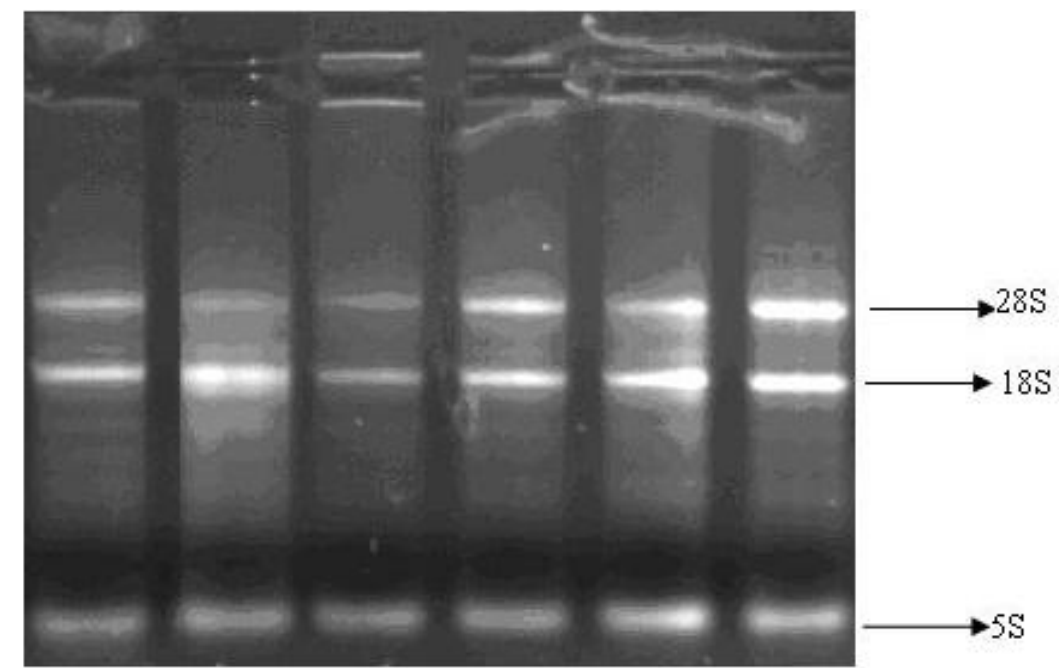

Figure 1. Agarose gel electrophoresis of total RNA.

Table 1. Primer sequence of IGF-I, MyoG, and 18S genes for RT-PCR.

\begin{tabular}{lllr}
\hline Gene & Reference sequence & Primers (forward primer SF, downstream primer SR) & Products (bp) \\
\hline IGF-I & M30653 & SF: TCCAGTTCGTGTGCGGAGA & 126 \\
& & SR: TCCTCAGATCACAGCTCCGG & 101 \\
MyoG & AF433651 & SF: AATGAAGCCTTCGAGGCCC & 187 \\
& & SR: CGCTCTATGTACTGGATGGCG & \\
& AY753190 & SF: CGGCTACCACATCCAAGGAA & \\
\hline
\end{tabular}

\section{RESULTS}

\section{Specificity of the amplified fragment}

The dissociation curve of IGF-I, MyoG, and 18s PCR products showed a sharp single 
peak (Figure 2). The potential for producing primer dimers and non-special products was avoided, since primers were highly specific and the PCR reaction was optimized. The solution temperatures of IGF-I, MyoG, and $18 \mathrm{~S}$ genes were $86.7^{\circ}, 87.2^{\circ}$, and $85.0^{\circ} \mathrm{C}$, respectively, and no amplification product was generated in the negative control. The efficiencies of IGF-I, MyoG, and 18S gene amplification were 99.7, 99.8, and 99.8\%, respectively (Figure 2).

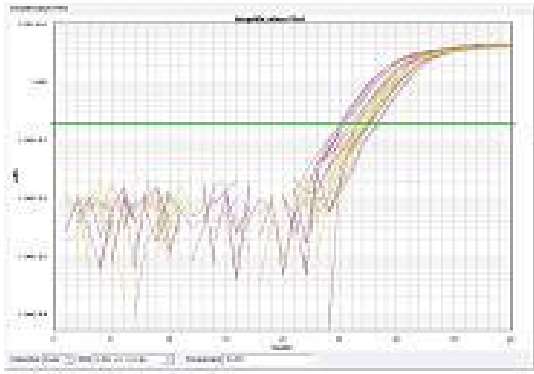

\section{A IGF-I amplification plot}

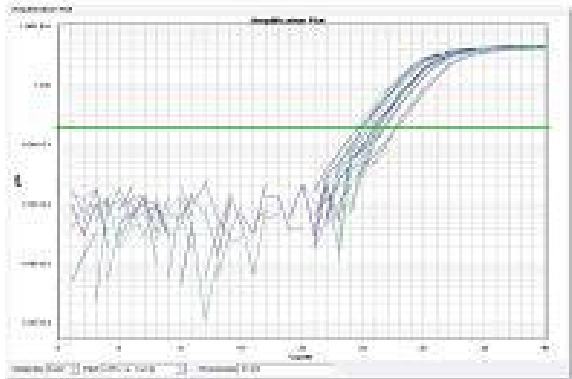

A MyoG amplification plot

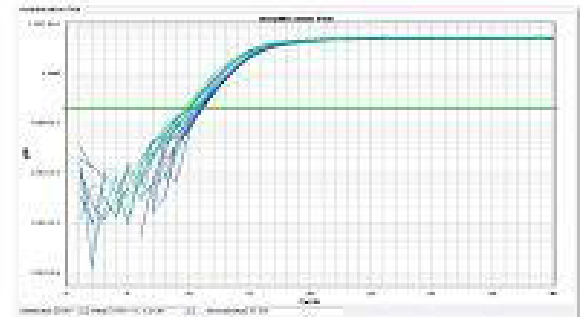

A18S amplification fil ot

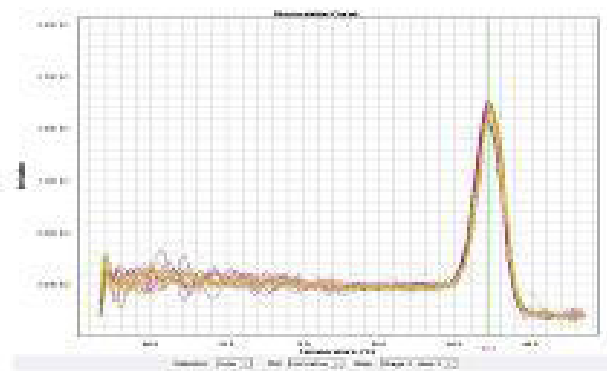

B IGF-I dissociation curve

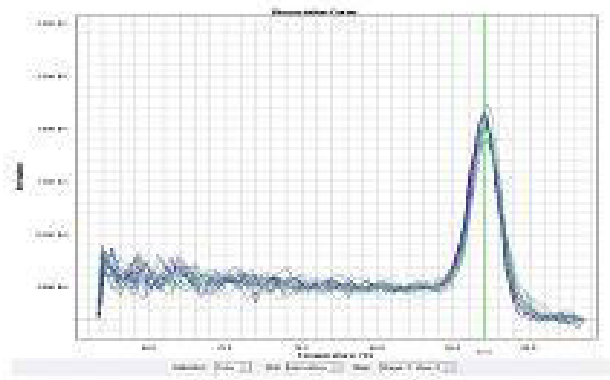

B MyoG disociation curve

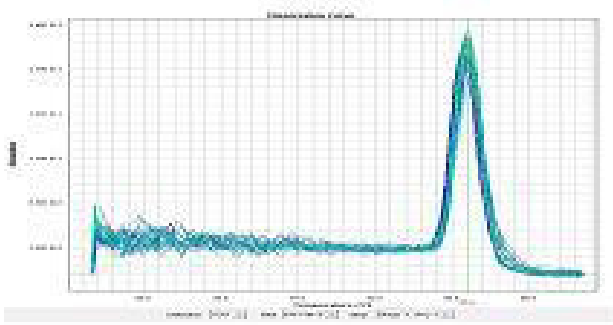

B 18 S dissociation curve

Figure 2. Amplification plot and dissociation curve of IGF-I, MyoG, and 18S.

\section{IGF-I gene expression}

The expression of the IGF-I gene in Hu sheep showed a significant or extremely significant difference between males and females at the two day-old $(0.01<\mathrm{P}<0.05)$, one month- 
old $(0.01<\mathrm{P}<0.05)$, and three month-old $(\mathrm{P}<0.01)$ stages (Table 2$)$. The results of multiple comparisons of different age groups within a sex are shown in Table 3. In females, IGF-I expression differed significantly between the six month-old stage and the four, three, two, one month-old, and two day-old stages $(\mathrm{P}<0.01)$. Similarly, expression in four months old females differed significantly with those of three months old and two days old females $(0.01$ $<\mathrm{P}<0.05$ ). In males, IGF-I expression differed significantly between the six month-old stage and the four, three, two month-old, and two day-old stages $(\mathrm{P}<0.01)$. In addition, one month old males showed significant differences when compared with three months old and two days old males $(0.01<\mathrm{P}<0.05)$. These results suggested that age and sex had significant effects on the expression of the IGF-I gene in sheep muscle tissue.

Table 2. Variance analysis of IGF-I expression between males and females in the same developmental stage
$\left(2^{-\triangle \Delta \mathrm{Ct}}\right.$ method).
\begin{tabular}{lccccccc}
\hline Gene & Gender & Two days old & One month old & Two months old & Three months old & Four months old & Six months old \\
\hline IGF-1 & $\begin{array}{c}\text { Female } \\
\text { Male }\end{array}$ & $1.264 \pm 0.112^{\mathrm{n}}$ & $2.095 \pm 0.501^{\mathrm{n}}$ & $1.204 \pm 0.123^{\mathrm{m}}$ & $0.730 \pm 0.048^{\mathrm{N}}$ & $1.180 \pm 0.242^{\mathrm{m}}$ & $1.350 \pm 0.310^{\mathrm{m}}$ \\
\hline
\end{tabular}

Serial of M (m) and N(n) shows the results of multiple comparison of the same stage of different sex. Means with the different lower-case within the same column shows that there are significant differences between different rows. Means with the different capital superscripts within the same column shows there are extremely significant differences between different rows.

Table 3. Variance analysis of IGF-I expression among different developmental stages in the same sex (2- $\triangle \Delta \mathrm{Ct}$ method).

\begin{tabular}{cccccccc}
\hline Gene & Gender & Two days old & One month old & Two months old & Three months old & Four months old & Six months old \\
\hline IGF-1 & Female & $1^{\mathrm{Bc}}$ & $1.383 \pm 0.168^{\mathrm{Bbc}}$ & $1.669 \pm 0.143^{\mathrm{Bbc}}$ & $1.983 \pm 0.368^{\mathrm{Bb}}$ & $2.060 \pm 0.295^{\mathrm{Bb}}$ & $3.445 \pm 0.598^{\mathrm{Aa}}$ \\
& Male & $1^{\mathrm{Bc}}$ & $2.264 \pm 0.541^{\mathrm{ABab}}$ & $1.599 \pm 0.163^{\mathrm{Bbc}}$ & $1.033 \pm 0.069^{\mathrm{Bc}}$ & $1.787 \pm 0.366^{\mathrm{Bbc}}$ & $3.403 \pm 0.780^{\mathrm{Aa}}$ \\
\hline
\end{tabular}

Serial of $\mathrm{A}(\mathrm{a}), \mathrm{B}(\mathrm{b})$ and $\mathrm{C}(\mathrm{c})$ shows the results of multiple comparison of same sex at different stages; Means with the different lower-case within the same row shows there are significant difference between different columns. Means with the different capital superscripts within the same row shows there are extremely significant differences between different columns.

IGF-I gene expression in male (rams) longissimus muscles tended to be higher than that in females (ewes) at all growth stages except for the three month-old stage (Figure 3). IGF-I gene expression in female longissimus dorsi gradually increased with the development of their growth, whereas changes in IGF-I gene expression in male longissimus dorsi were unstable (Figure 4).

\section{MyoG gene expression}

There was no significant difference $(\mathrm{P}>0.05)$ in the expression of the MyoG gene between males and females at any growth stage, although males showed higher MyoG gene expression levels compared to females (Table 4). Multiple comparison analysis of the same sex at different growth stages showed significant differences in the expression of MyoG between females at the six month-old stage with the four, two month-old, and two day-old stages $(0.01<\mathrm{P}<0.05)$, the three month-old stage with the one month-old stage $(0.01<\mathrm{P}<0.05)$, 
the four month-old stage with the three month-old and one month-old stages $(0.01<\mathrm{P}<0.05)$, and the two month-old stage with the one month-old and three month-old stages $(0.01<\mathrm{P}<$ 0.05). Similarly, extremely significant differences were found when six months old females were compared to two and four months old females, when four months old females were compared to three months old females, and when three months old females were compared to two days old females $(\mathrm{P}<0.01)$. The expression of MyoG in males showed extremely significant differences when comparing six months old individuals to two days old individuals $(\mathrm{P}<0.01)$ (Table 5).

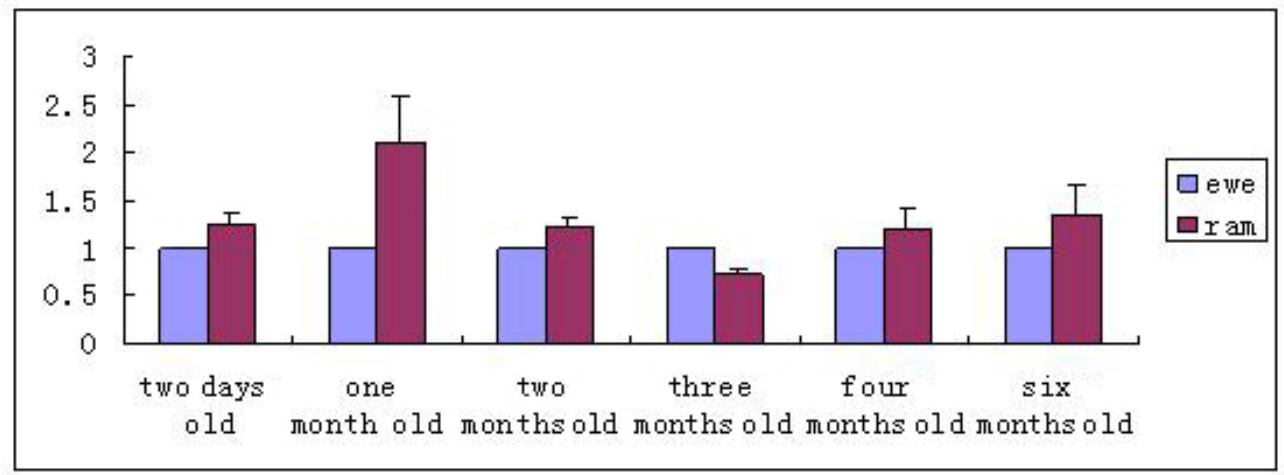

Figure 3. IGF-I gene expression in males and females of Hu sheep at the same age $\left(2^{-\triangle \Delta \mathrm{Ct}}\right.$ method, ewe for the control group).
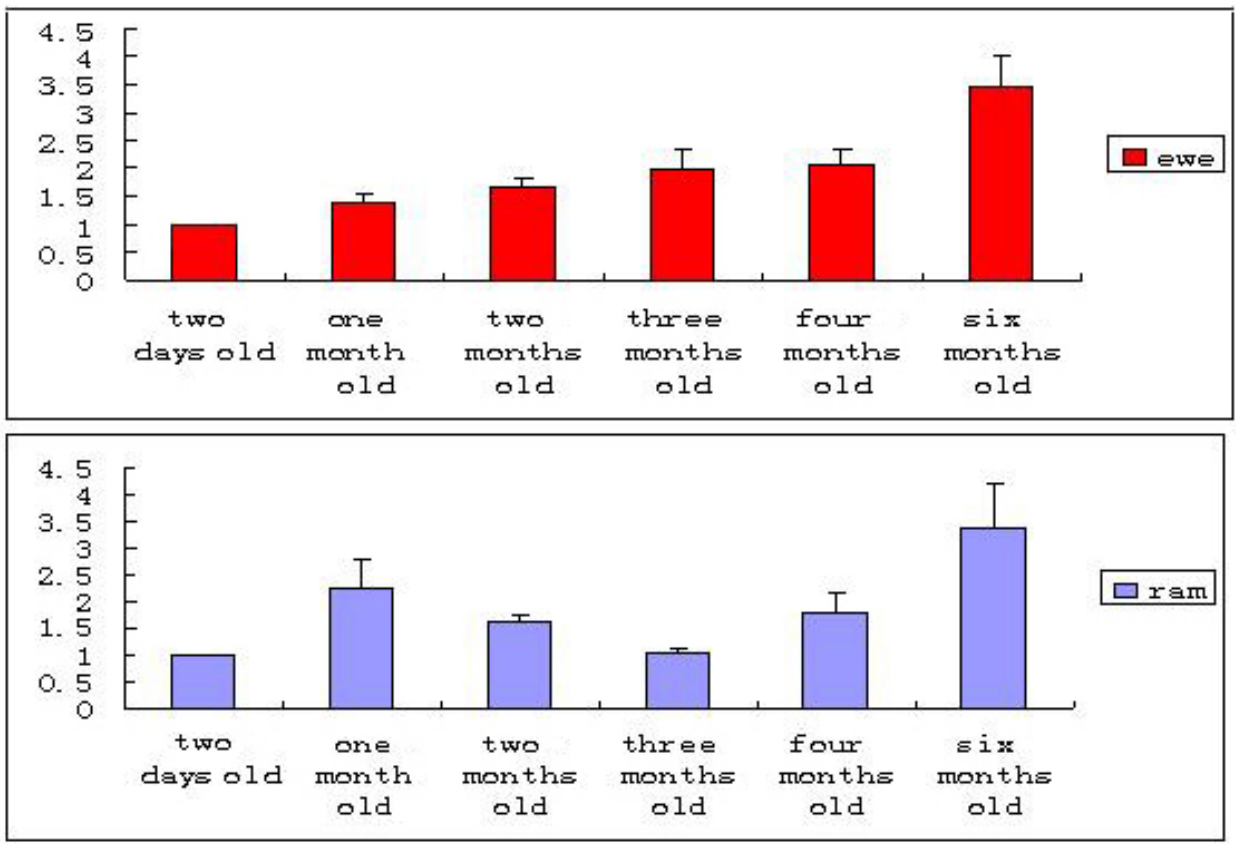

Figure 4. Changes of IGF-I expression among Hu sheep different developmental stages in the same gender $\left(2^{-\triangle \Delta \mathrm{Ct}}\right.$ method, 2-day for the control group, $\mathrm{A}=$ ewe, $\mathrm{B}=$ ram). 
Table 4. Variance analysis of MyoG expression between males and females in the same developmental stage $\left(2^{-\triangle \Delta \mathrm{Ct}}\right.$ method).

\begin{tabular}{lccccccc}
\hline Gene & Gender & Two days old & One month old & Two months old & Three months old & Four months old & Six months old \\
\hline MyoG & $\begin{array}{c}\text { Female } \\
\text { Male }\end{array}$ & $1.437 \pm 0.338^{\mathrm{m}}$ & $1.096 \pm 0.277^{\mathrm{m}}$ & $1.235 \pm 0.238^{\mathrm{m}}$ & $1.075 \pm 0.201^{\mathrm{m}}$ & $1.536 \pm 0.257^{\mathrm{m}}$ & $1.013 \pm 0.138^{\mathrm{m}}$ \\
& & & $1^{\mathrm{m}}$ & & & $1^{\mathrm{m}}$ & \\
\end{tabular}

Serial of $M(m), N(n)$ shows the results of multiple comparison of same stage of different sex. Means with the different lower-case within the same column shows that there are significant differences between different rows. Means with the different capital superscripts within the same column shows that there are extreme significant differences between different rows.

Table 5. Variance analysis of MyoG expression among different developmental stages in the same sex $\left(2^{-\triangle \Delta \mathrm{Ct}}\right.$ method).

\begin{tabular}{lccccccc}
\hline Gene & Gender & Two days old & One month old & Two months old & Three months old & Four months old & Six months old \\
\hline MyoG & Female & $1^{\mathrm{Bc}}$ & $1.731 \pm 0.124^{\mathrm{ABab}}$ & $1.381 \pm 0.084^{\mathrm{ABbc}}$ & $2.053 \pm 0.505^{\mathrm{Aab}}$ & $0.984 \pm 0.129^{\mathrm{Bc}}$ & $2.276 \pm 0.226^{\mathrm{Aa}}$ \\
& Male & $1^{\mathrm{Bb}}$ & $1.809 \pm 0.457^{\mathrm{ABab}}$ & $1.634 \pm 0.315^{\mathrm{ABab}}$ & $1.380 \pm 0.258^{\mathrm{ABab}}$ & $1.379 \pm 0.231^{\mathrm{ABab}}$ & $2.161 \pm 0.295^{\mathrm{Aa}}$ \\
\hline
\end{tabular}

Serial of $A(a), B(b)$ and $C(c)$ shows the results of multiple comparison of same sex at different stages; Means with the different lower-case within the same row shows that there are significant difference between different columns. Means with the different capital superscripts within the same row shows that there are extremely significant differences between different columns.

MyoG gene expression levels in male longissimus muscles tended to be higher than those of ewes at all growth stages, except for the six month-old stage (Figure 5). However, the changes in MyoG gene expression in female and male longissimus dorsi were unstable (Figure 6).

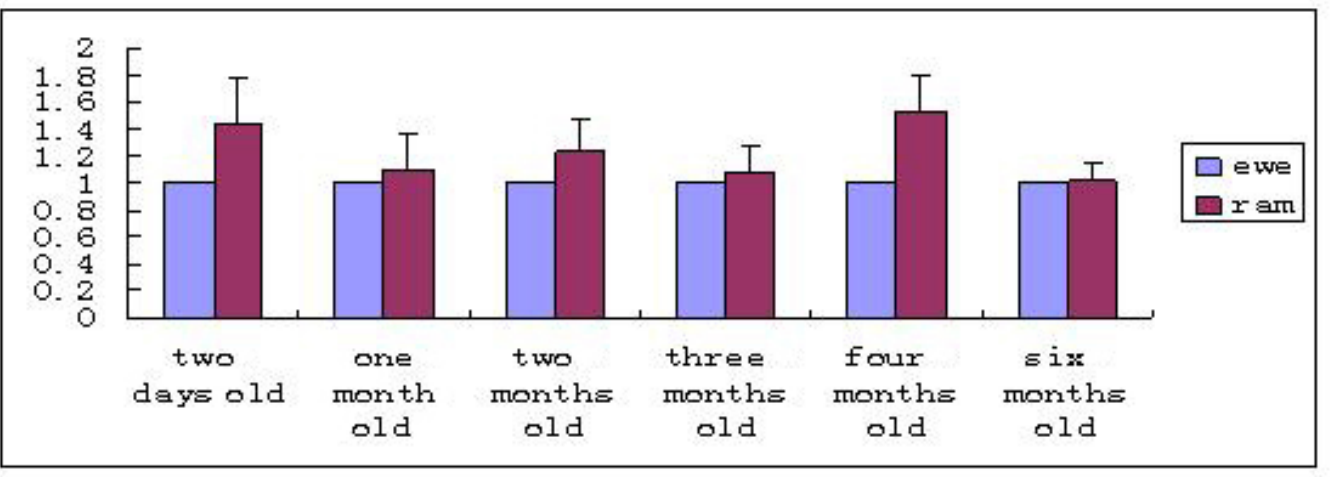

Figure 5. MyoG gene expression in males and females of Hu sheep in the same growth stage $\left(2^{-\triangle \Delta \mathrm{Ct}}\right.$ method, ewe for the control group).

\section{Association of IGF-I and MyoG gene expressions with carcass traits}

IGF-I gene expression was significantly and positively correlated with live weight $(\mathrm{P}<0.01)$ and carcass weight $(0.01<\mathrm{P}<0.05)$, and was non-significantly but positively correlated with net meat weight $(\mathrm{P}>0.05)$. In contrast, MyoG gene expression was non- 
significantly and positively correlated with live weight, carcass weight, and net meat weight $(\mathrm{P}>0.05)$. An extremely significant positive correlation was found among the carcass traits $(\mathrm{P}<0.01)$. Furthermore, there was an extremely significant positive correlation between the expressions of IGF-I and MyoG genes $(\mathrm{P}<0.01)$ (Table 6).
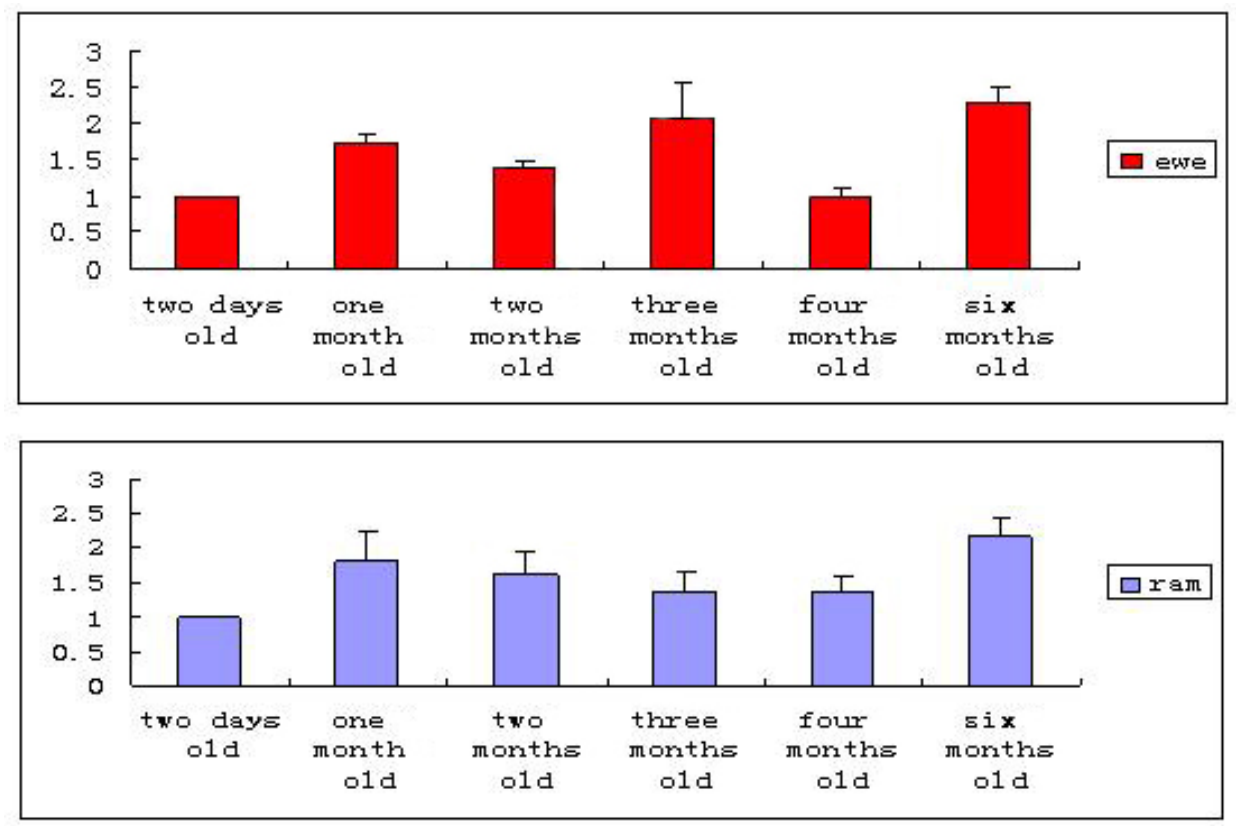

Figure 6. Changes of MyoG expression among Hu sheep different developmental stages in the same gender $\left(2^{-\triangle \Delta C t}\right.$ method, 2 days for the control group, $\mathrm{A}=\mathrm{ewe}, \mathrm{B}=\mathrm{ram}$ ).

Table 6. Association of IGF-I and MyoG genes expression with carcass traits.

\begin{tabular}{|c|c|c|c|c|c|}
\hline Index & IGF-I & MyoG & Live weight & Carcass weight & Net meat weight \\
\hline IGF-I & 1 & $0.464 * *$ & $0.450^{* *}$ & $0.409 *$ & 0.247 \\
\hline MyoG & $0.464 * *$ & 1 & 0.249 & 0.246 & 0.083 \\
\hline Live weight & $0.450 * *$ & 0.249 & 1 & $0.993^{* *}$ & $0.824 * *$ \\
\hline Carcass weight & $0.409^{*}$ & 0.246 & $0.993 * *$ & 1 & $0.848 * *$ \\
\hline Net meat weight & 0.247 & 0.083 & $0.824^{* *}$ & $0.848^{* *}$ & 1 \\
\hline
\end{tabular}

*There is significant relationship between two different index $(0.01<\mathrm{P}<0.05)$. **There is extreme significant relationship between two different index $(\mathrm{P}<0.01)$.

\section{DISCUSSION}

IGF-1 is an important regulatory factor for body growth, development, and metabolism. IGF-I mRNA expression in longissimus dorsi of pigs showed no significant difference (P $>0.05$ ) between males and females (Xu, 2002). In the present study, with the exception of the three month-old stage, IGF-I was more highly expressed in male longissimus dorsi compared to females at different growth stages after birth. This may indicate that IGF-I has a greater effect on early sheep muscle growth in males than it does in females. Gerrard et al. (1998) demon- 
strated that IGF-I mRNA expression increased gradually from the 44th day of pregnancy to the late pregnancy stage in pig fetal semitendinosus muscles, further increased after birth, reaching a peak at 21 days old, and then declined in adulthood. Gotz et al. (2001) showed that the expression levels of IGF-I were similar in pig skeletal muscle and in blood from 11 to 22 weeks old. Xu (2002) showed that the expression of IGF-I did not change significantly from birth to one month old in the longissimus dorsi of both Erhualian and Yorkshire pigs, and then significantly increased from the one month old to the three month-old stage, and remained at a high level. Gu et al. (2009) found that the expression of IGF-I increased gradually after birth in both Landrace and Meishan pigs. Huang and Xie (2009) found that the expression of IGF-I showed large fluctuations in Xinjiang fine-wool sheep; it slightly declined from the two day-old to the one month-old stage, reached a peak at two months-old, and then dropped to the lowest level before increasing again over the subsequent growth stages. In the present study, the expression of the IGF-I gene in ewes' longissimus dorsi gradually increased with growth development and reached its peak at six months old, confirming results obtained by Gu et al. (2009). In agreement with Huang and Xie (2009), the expression of IGF-I in rams increased during the first two stages, dropped to the level of the two days-old stage at three months old, and then gradually increased thereafter in the following stages, reaching its peak at the six months-old stage. IGF-I functions to increase amino acid utilization during protein synthesis and inhibits protein degradation, and thus, accordingly, promotes the proliferation of bone and muscle cells. Much research has been conducted recently regarding the correlation between polymorphisms of the IGF-I gene with carcass traits of poultry and pigs. Although several studies have investigated the expression of IGF-I in sheep muscle, few have evaluated the correlation between this expression with different developmental stages and carcass traits. In the present study, the relative expression of the IGF-I gene showed an extremely significant positive correlation with live weight $(\mathrm{P}<0.01)$ and with carcass weight $(0.01<\mathrm{P}<0.05)$.

Myogenin $(\mathrm{MyoG})$ is an important transcription factor that regulates skeletal muscle development, and is expressed in all skeletal muscle cells in the MyoD family. Genetic variation of MyoG might be related with myogenesis, and it could ultimately lead to variations in meat quality. Yablonka-Reuveni and Paterson (2001) noted that in chicken embryo-type myoblast cultures, MyoG appeared to be terminally differentiated, while in adult-type myoblast cultures, MyoG was expressed in early myogenic cell lineages. In the present study, the expression of MyoG in rams' longissimus dorsi was non-significantly $(\mathrm{P}>0.05)$ higher than that in ewes after birth. In contrast, extremely significant $(\mathrm{P}<0.01)$ or significant $(0.01$ $<\mathrm{P}<0.05)$ differences were observed between males and females at the same growth stage in Erhualian pigs and Hu sheep (Yang et al., 2006; Sun et al., 2010). The reason for these different results might be related to the choice of experimental methods. Yang et al. (2006) and Sun et al. (2010) both used the semi-quantitative gray scale analysis method, while we used the 2- $\Delta \Delta \mathrm{Ct}$ method to analyze relative expression differences. Shan et al. (2009) investigated MyoG mRNA expression in longissimus dorsi muscles of Jinhua and Landrace pigs, and found that the expression of the MyoG gene increased with age and lean meat percentage of the carcass. In contrast, Hasty et al. (1993) found that the expression of the MyoG gene decreased with age and lean meat percentage of the carcass in Landrace pigs, which were negatively correlated, but did not display breed differences. In the present study, the expression of the MyoG gene was non-significantly $(\mathrm{P}>0.05)$ and positively correlated with live weight, carcass, and net meat weight. 
During the skeletal muscle growth process, IGF-I regulates the growth of skeletal muscle and stimulates myoblast terminal differentiation by inducing the expression of $\mathrm{MyoG}$ (Xue, 2004). In the present study, we found that the expression of IGF-I and MyoG genes were positively correlated, and the expression of these two genes in muscle affected carcass traits. This study could provide a theoretical basis for further research and provides genetic data for Hu sheep carcass trait breeding.

\section{ACKNOWLEDGMENTS}

Research supported by the projects of domesticated animals platform of the Ministry of Science and Technology of China, Jiangsu Agricultural Science, and Technology Support Program of China (\#BE2012331), the Graduate Education Innovation Project of Jiangsu Province of China (\#CXLX13-919), the Project Funded by the Priority Academic Program Development of Jiangsu Higher Education Institutions, the Project Jiangsu Province Engineering Research Center of China (\#BM2012308), the Project of Six Peak of Talents in Jiangsu Province, and Yangzhou University Students Innovation Training Plan (\#B1261).

\section{REFERENCES}

Cao Y, Yao Z, Sarkar D, Lawrence M, et al. (2010). Genome-wide MyoD binding in skeletal muscle cells: a potential for broad cellular reprogramming. Dev. Cell 18: 662-674.

Faralli H and Dilworth FJ (2012). Turning on myogenin in muscle: a paradigm for understanding mechanisms of tissuespecific gene expression. Comp. Funct. Genomics 2012: 836374.

Gerrard DE, Okamura CS, Ranalletta MA and Grant AL (1998). Developmental expression and location of IGF-I and IGF-II mRNA and protein in skeletal muscle. J. Anim. Sci. 76: 1004-1011.

Gotz W, Dittjen O, Wicke M, Biereder S, et al. (2001). Immunohistochemical detection of components of the insulin-like growth factor system during skeletal muscle growth in the pig. Anat. Histol. Embryol. 30: 49-56.

Gu YR, Zhang K, Li MZ, Li XW, et al. (2009). Developmental expression changes of insulin-like growth factors (IGFs) system genes in longissimus dorsi muscle of two pig breeds. Yi. Chuan 31: 837-843.

Hasty P, Bradley A, Morris JH, Edmondson DG, et al. (1993). Muscle deficiency and neonatal death in mice with a targeted mutation in the myogenin gene. Nature 364: 501-506.

Huang ZG and Xie Z (2009). Developmental changes of IGF-I mRNA expression level in sheep muscle. Agr. Sci. Technol. 10: 68-72.

Kajimoto Y and Rotwein P (1991). Structure of the chicken insulin-like growth factor I gene reveals conserved promoter elements. J. Biol. Chem. 266: 9724-9731.

Liu L (2007). Relative quantitative detection of HLA-G mRNA expression in patients with endometriosis by $2-\Delta \Delta \mathrm{CT}$ method. China's Eugenic Genet. Mag. 15: 25-26.

Meadows E, Flynn JM and Klein WH (2011). Myogenin regulates exercise capacity but is dispensable for skeletal muscle regeneration in adult mdx mice. PLoS One 6: e16184.

Mikawa S, Yoshikawa G, Aoki H, Yamano Y, et al. (1995). Dynamic aspects in the expression of the goat insulin-like growth factor-I (IGF-I) gene: diversity in transcription and post-transcription. Biosci. Biotechnol. Biochem. 59: 87-92.

Reyna XF, Montoya HM, Castrellon VV, Rincon AM, et al. (2010). Polymorphisms in the IGF1 gene and their effect on growth traits in Mexican beef cattle. Genet. Mol. Res. 9: 875-883.

Rose MT (2002). The somatotropic axis of the dairy cow revisited. Anim. Sci. J. 73: 13-19.

Rothschild MF, Messer LA and Vincent A (1997). Molecular approaches to improved pig fertility. J. Reprod. Fertil Suppl. 52: $227-236$

Rotwein P, Pollock KM, Didier DK and Krivi GG (1986). Organization and sequence of the human insulin-like growth factor I gene. Alternative RNA processing produces two insulin-like growth factor I precursor peptides. J. Biol. Chem. 261: 4828-4832.

Shan LL, Zhang M, Miao ZG, Wang LJ, et al. (2009). Mogenin mRNA abundance in longissimus dorsi muscle of Jinhua pig and Landrace pig. Chin. J. Vet. Sci. 29: 374-377. 
Shimatsu A and Rotwein P (1987). Mosaic evolution of the insulin-like growth factors. Organization, sequence, and expression of the rat insulin-like growth factor I gene. J. Biol. Chem. 262: 7894-7900.

Sun W, Wang P, Ding JT, Ma YH, et al. (2010). Development changes of gene expression of Myostatin and Myogenin genes and their association analysis with carcass traits in Hu sheep. Sci. Agric. Sin. 43: 5129-5136.

Tosh JJ and Kemp RA (1994). Estimation of variance components for lamb weights in three sheep populations. J. Anim. Sci. 72: 1184-1190.

Xu QF (2002). Regulation and Expression of Target Genes for Growth Hormone Action in Liver and Muscle of Pigs. Nanjing Agricultural University, $\mathrm{PhD}$ thesis.

Xue HL (2004). Studies on Molecular Genetic Polymorphisms of the IGF-I Gene and MyoG Gene in Pigs. Shanxi Agricultural University, $\mathrm{PhD}$ thesis.

Yablonka-Reuveni Z and Paterson BM (2001). MyoD and myogenin expression patterns in cultures of fetal and adult chicken myoblasts. J. Histochem. Cytochem. 49: 455-462.

Yang XJ, Chen J, Xu QF, Wei XH, et al. (2006). Development changes of Myostatin and Myogenin genes expression in longissimus dorsi muscle of Erhualian and Large White pigs. J. Nanjing Agr. Univ. 29: 64-68.

Zhang CX, Zhang W, Luo HL, Yue WB, et al. (2008). A new single nucleotide polymorphism in the IGF-I gene and its association with growth traits in the Nanjiang Huang goat. Asian-Aust. J. Anim. Sci. 21: 1073-1079.

Zhang JH (2003). Present situation and development counter measures of sheep keeping in China. Grass Feeding Livest. 1: $1-4$. 